\title{
The Research of Creative Problem Solving Mode Based on TRIZ

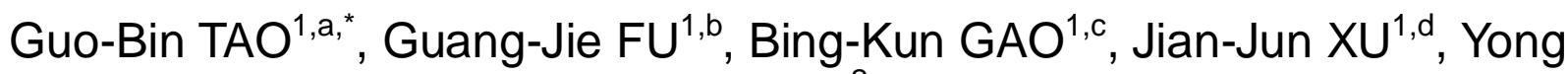 ZHANG ${ }^{2, e}$ \\ ${ }^{1}$ Faculty of Electricity and Information Engineering, Northeast Petroleum University \\ ${ }^{2}$ Faculty of Electronic Science, Northeast Petroleum University, Daqing Heilongjiang, 163318, China

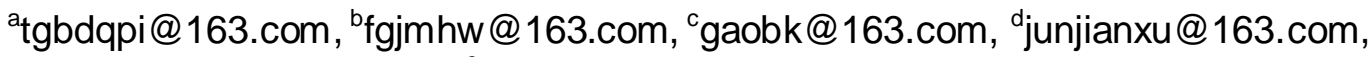 ezhangyong@nepu.edu.cn \\ ${ }^{*}$ Corresponding author
}

Keywords: TRIZ theory, Innovation, Application framework.

\begin{abstract}
TRIZ theory is more universal, practical and feasible than other innovative theory. In this paper, it is discussed that TRIZ theory supports innovation activities by comparison with the traditional and innovative ways. TRIZ theory application framework for solving innovation problems is presented based on the research of the nine classical theory of TRIZ. At last, the use of such framework is explained by a project example.
\end{abstract}

\section{Introduction}

In the era of knowledge economy, the importance of innovation has been realized by many countries and people in the world. As early as 1982, Japan proposed the "creative development is a guarantee to the 21st century". Pusey, president of Harvard University, said: "whether a person has the creativity is a first-class talent and second-rate talent watershed". Comrade Zemin Jiang pointed out: "The creation is the soul of a nation's progress, inexhaustible power of the country's prosperity, it is difficult to stand in the advanced nations in the world for a national without innovation capability." Seventeenth Party Congress proposed to improve the capability of independent innovation and build an innovation-oriented country, institutions of higher learning should be further strengthened college students' innovative consciousness and innovative ability cultivation[1] in order to meet the needs of building an innovative country.

\section{The application advantage of TRIZ theory}

The innovation of the traditional methods, such as trial and error, brainstorming, etc., has played a big role in the process of promoting scientific and technological progress, but these methods have obvious defects. Trial and error method is the innovation of the pure experience, and it depends on the personal experience and knowledge, and there is no direction in the process of innovation, so efficiency of this method is very low; Brainstorming method is produced based on trial and error method improvement, although brainstorming method has a certain improvement compared with the trial and error method, and it can help overcome the inertia of thinking[2], but defects that it can not control brainstorming often make the problem in the process of thinking into the whirlpool, so the problem cannot be solved for a long time, the efficiency is still not high.

TRIZ theory[3] is proposed by former Soviet inventor Altshuller at 1946. Altshuller setted up this innovative theories based on the analysis of nearly 250 million copies of high level of invention patent in the world and compositing the principles and rules of the multidisciplinary field. TRIZ theory reveals the inherent law of the invention, and it can help people overcome the blindness, solving technical problems, empirical and contingencies based on mastering these laws. TRIZ theory is recognized as the best tool of guiding the innovation in the world, and learning and mastering TRIZ theory is an effective way to rapidly improve the innovation ability. 


\section{TRIZ theory and its application framework}

The TRIZ theory[4] contains many systems, science and rich creative thinking methods and inventions operability analysis method, it is shown in Figure 1. After more than half a century of development, TRIZ theory has a maturity of nine classic theoretical system for solving the issue of innovation and invention.

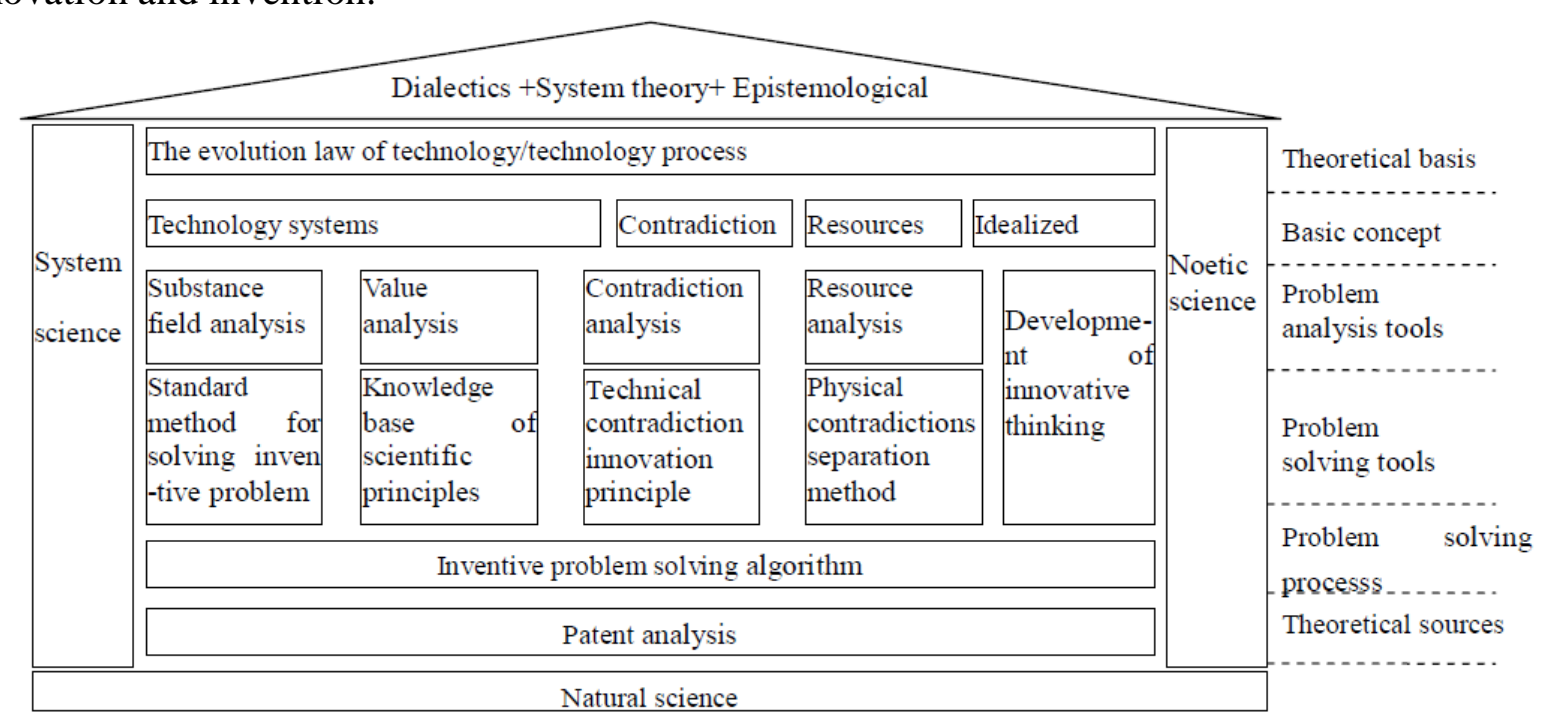

Figure 1 TRIZ theory framework

Correct understanding and familiar the nine classic theoretical system of TRIZ theory, learning to master the contradictions solutions and solving step and the application method of TRIZ theory is the key to the application of TRIZ theory.

\section{The application of TRIZ theory}

\section{Existing problems of technology system's physical description}

A workshop gets an order of large metal parts for heat treatment. To do this work, crane drivers must tune out red iron from blast furnace, which was transported to the top of the tank and put it into a slot.

After a few days of work, crane driver complained to the owner: "I'm so dry I can hardly breathe from the closely roof of the control room, so the smoke rising from tank inside floats to me, I quit."

When dealing with small parts, smoke had no problem, the workshop ventilation equipment to meet the requirements; Now, when dealing with large components, smoke become a major problem. Since the process can not be changed, the boss is facing a typical management situation: come up with a way to solve the problem, but he did not know how to solve.

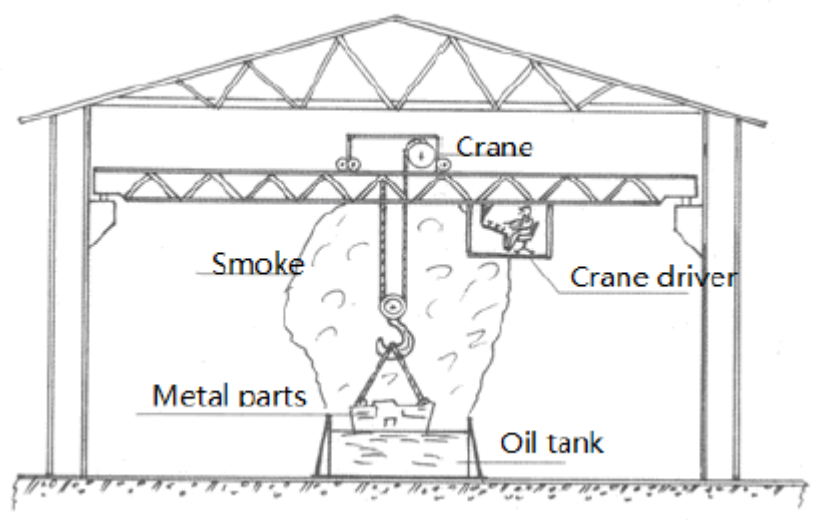

Figure.2. Metal parts processing system diagram 


\section{Solution procedure of using TRIZ}

Step1.The name of Technical System: Metal parts processing system

Step 2.The function of Technical System: Large-scale metal parts oil processing

Step 3.Technology system decomposition

System components: tanks, metal parts, cranes, crane drivers, smoke, air.

Technical systems can be decomposed into five subsystem, substance substance - field model is shown in figure 3.

Substance 1:S1 is metal parts; S2 is the oil in the tank; F is thermal field;

Subsystem 2: S1 is oil; S2 is air; F is thermal field;

Subsystem 3: S1 is crane driver; S2 is smoke; F machinery (diffusion);

Subsystem 4: S1 is metal parts; S2 is crane; F mechanical field;

Subsystem 5: S1 is the crane; S2 is crane driver; F is the electromagnetic plant (control).

Step 4.The determination of the key subsystems

Subsystem 2 and 3 are all exist technical contradiction, technical contradiction of subsystem 2 is the fundamental problem, technical contradictions of subsystem 3 is derivative problem, so the key subsystem is subsystem 2 .

Both subsystem 2 and subsystem 3 substance - field model are complete models of harmful effect, and complete models of harmful effect is shown in figure 4.

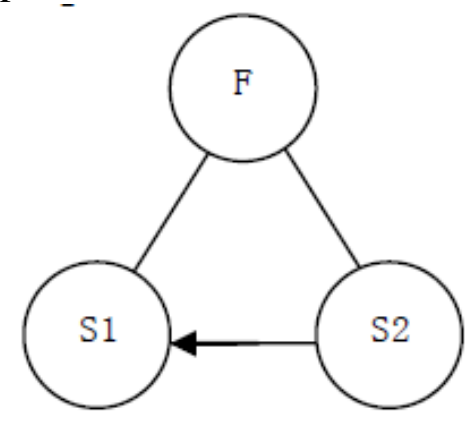

Figure.3. substance-field model

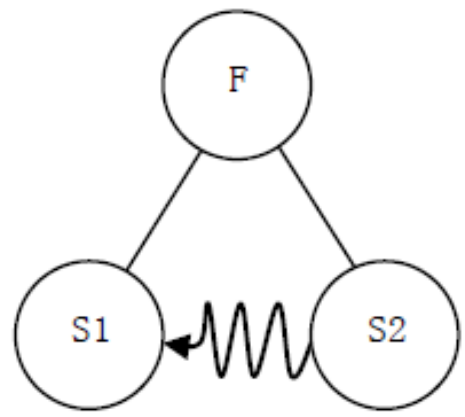

Figure.4. Complete model of harmful effect

General solution of complete model of the harmful effects is shown in figure 5 and figure 6 .

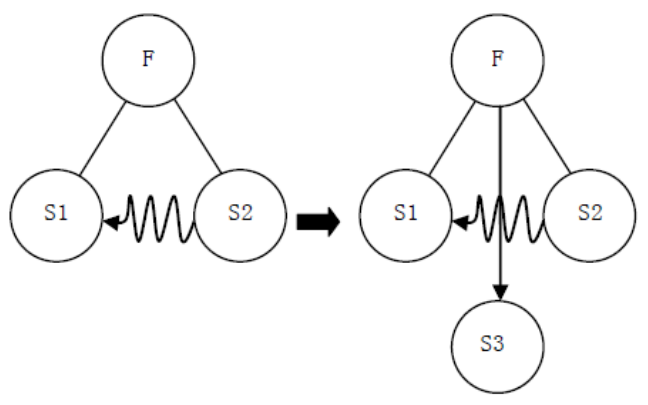

Figure.5. The 1 st general solution

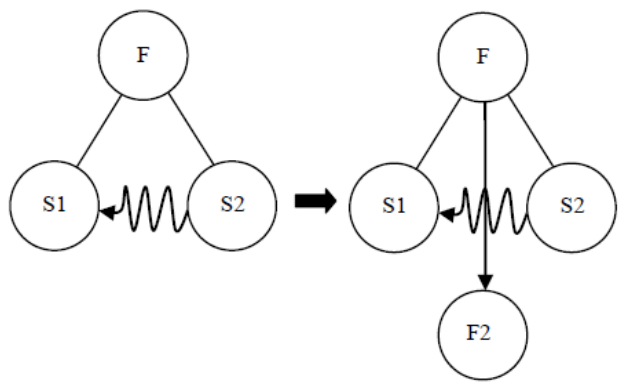

Figure.6. The 2nd general solution

The solution of subsystem 3 technology contradiction:

A. Plus a gas mask (Method 1)

B. Plus a blower (Method 2)

Subsystem 2 technology contradictory solutions: Consider to add a cover (isolated oil and air).

Step 5.Technical contradictory description

When the hot metal parts are placed in oil tank, oil in it is heated dense smoke, pollute the environment. 
Step 6.The properties of the technical system should be improved and corresponding of the engineering parameters.

(1)The physical description of technical system characteristics which should be improved: removing or reducing the smoke.

(2)The engineering parameters will be improved of technical systems: harmful factors of the substance generation.

Step 7.The characteristics of the technical system has been deteriorated and the corresponding engineering parameter.

(1)Analysis: According to the general solution of the harmful effects of the full model, Regardless of plusing substance or field, it will increase complexity of the system, the program of adding a cover, will affect the weight of the moving substance.

(2)The engineering parameters for the deterioration of technical systems: the complexity of the system (weight of moving substances).

Step 8.Searching for the Altshuller contradiction matrix

1)Technical contradiction 1 (harmful factors of substances producted to the complexity of the system)

(1) Finding Altshuller contradictory matrix results is shown in Table 1.

Table.1. Technical contradiction 1

\begin{tabular}{c|c|c|c}
\hline \hline $\begin{array}{c}\text { Technical } \\
\text { Contradictions }\end{array}$ & $\begin{array}{c}\text { Table } \\
\text { Crosspoint }\end{array}$ & $\begin{array}{c}\text { Recommended } \\
\text { principle }\end{array}$ & $\begin{array}{c}\text { Name of } \\
\text { Principle }\end{array}$ \\
\hline $\begin{array}{c}\text { The harmful } \\
\text { factors of } \\
\text { substance - the } \\
\text { complexity of the } \\
\text { system }\end{array}$ & $31 \times 36$ & 19 & $\begin{array}{c}\text { Cyclical action } \\
\text { principle }\end{array}$ \\
\cline { 3 - 4 } & & 31 & $\begin{array}{c}\text { Segmentation } \\
\text { principle }\end{array}$ \\
\cline { 2 - 4 } & $\begin{array}{c}\text { The porous } \\
\text { material principle }\end{array}$ \\
\hline \hline
\end{tabular}

(2)Recommended principle explanation

(1) Principle explanation of cyclical effect

-With periodic or pulsating action instead of a continuous movement;

-If the action has been periodic, the frequency should be changed;

-Using the gap among pulsation to perform another operation.

(2) Segmentation principle

-Dividing the substance into separate parts

-To become combined of substances (easy to disassemble and assemble);

-Increasing the extent of the substance to be divided.

(3) The porous material principle

-An substance porous or add porous elements;

-If an substance is already porous, take advantage of these holes to introduce useful substances or function.

(3)Analysze the feasibility of recommended principle

(1) The principle of periodic effect analysis: a cover opening and closing with the periodic (not ideal);

(2) Segmentation principle analysis:Overall - each local - liquid - gas (to be selected);

(3) Principle of porous materials: use a cover with holes (not feasible).

2)Technical Contradictions 2(harmful factors of substances generated to weight of moving substances)

(1) Finding Altshuller contradictory matrix results is shown in Table 2. 
Table.2. Technical contradiction 2

\begin{tabular}{c|c|c|c}
\hline \hline $\begin{array}{c}\text { Technical } \\
\text { Contradictions }\end{array}$ & $\begin{array}{c}\text { Table } \\
\text { Crosspoint }\end{array}$ & $\begin{array}{c}\text { Recommended } \\
\text { principle }\end{array}$ & Name of Principle \\
\hline \multirow{2}{\text{Substances}}{$\begin{array}{c}\text { generated } \\
\text { harmful factors } \\
\text { - weight of } \\
\text { moving } \\
\text { substances }\end{array}$} & $31 \times 1$ & 19 & Cyclical action principle \\
\cline { 2 - 3 } & & 15 & $\begin{array}{c}\text { Change harm into advantage } \\
\text { principles }\end{array}$ \\
\cline { 2 - 4 } & & 39 & $\begin{array}{c}\text { Dynamic characteristics } \\
\text { principle }\end{array}$ \\
\hline \hline
\end{tabular}

(2)Recommended principle explanation

(1) Principle explanation of cyclical effect, as already discussed.

(2) Change harm into advantage principles

-Using of harmful factors, to obtain beneficial results;

-The combination of two harmful factors offset the harmful factors;

-Increasing amplitude of harmful factors until the harmful disappear.

(3) The principle of Dynamic characteristics

-An substance or its environment automatically adjust to achieve the best performance in each stage of the action;

-The substance is divided into several parts, may change the relative position between the parts;

-The stationary substance is changed to be movable, or with adaptive.

(4)Inertia environment principle

-Instead of the usual environment with an inert gas atmosphere;

-Complete the process in vacuum.

(3)Analysze the feasibility of recommended principle

(1)Principle explanation of cyclical effect, as already discussed.

(2) Principle analysis of the changes in physical or chemical parameters: solid cover - liquid cover (to be selected)

(3) Analysis of the dynamic characteristics of the principle: change the relative position - Dynamic cover (not sure)

(4) Analysis of the inertia environment principle:use inert gas to be a cover (to be selected)

Step 9.Determine solutions, and evaluate the idealization degree of solutions

It is showed from the above analysis, inventional principles and segmentation principle, changing of the physical or chemical parameters Principle, Inertia environment principle is helpful to solve the problem, and it can adopt the measure by adding the liquid or inert gas (dynamic cover) to the surface of the air and the oil tank to solve the technical contradictions. Complexity of the system did not increase (or increased very little), but completely clear harmful factors, a high degree of idealization of the program.

\section{Conclusion}

The TRIZ theory is an solving method of innovations problem,the theory includes nine classical theoretical system and a number of analytical methods. How to effectively make good use of TRIZ theory for innovation and invention is a serious problem, based on depth study of the system the nine classical theory of TRIZ theory, proposed general framework of TRIZ Theory. Using this framework can efficiently innovation and evaluation with TRIZ theory, for the application of TRIZ theory provides the foundation and contribute to research and promotion of TRIZ. 


\section{Acknowledgement}

This research was financially supported by higher education teaching reform project (project name: The research of collaborative innovation mechanism based on college students' innovative practice (Grant NO. JG2014010635) of Heilongjiang province of China.

\section{References}

[1] Root Ridge Altshuller,Lin Yue et translation. Trick to implement technology innovation of TRIZ. Harbin: Heilongjiang Science and Technology Press, 2008.

[2] Li Huijun, Guo Feng. TRIZ promote the exploration of creative thinking. Shijiazhuang Railway Institute(Social Science). $2^{\text {nd }}$, pp.89-92. 2008.

[3] Qingliang Yang. Invention is a born-TRIZ theory Keys. Beijing: Machinery Industry Press, 2006.

[4] Xinjun Zhao. TRIZ and it's application. Beijing: Chemical Industry Press, 2004. 